\title{
Knowledge about COPD among users of primary health care services
}

This article was published in the following Dove Press journal:

International Journal of COPD

17 December 2014

Number of times this article has been viewed

\section{Maria Conceição de Castro Antonelli Monteiro de Queiroz' Maria Auxiliadora Carmo Moreira' Jose R Jardim² Maria Alves Barbosa ${ }^{3}$ Ruth Minamisava ${ }^{3}$ Heicilainy Del Carlos Gondim 4 Flávia Castro Velasco ${ }^{4}$ Maria Vitoria Carmo Penhavel $^{5}$}

'Department of Respiratory Medicine, School of Medicine, Federal University of Goiás, Goiânia, Brazil; ${ }^{2}$ Respiratory Division at Escola Paulista de Medicina, Federal University of São Paulo, Brazil; ${ }^{3}$ School of Nursing, Federal University of Goiás, ${ }^{4}$ Pulmonology Department, Goiânia General Hospital, Goiânia, Brazil; ${ }^{5}$ School of Medicine, University of Brasilia, Brasilia, Brazil
Correspondence: Maria Conceição de Castro Antonelli Monteiro de Queiroz Department of Respiratory Medicine, School of Medicine, Federal University of Goias, First Avenue, s/n - East Sector University, 74605-020

Goiânia, Goiás, Brazil

Tel +55 6232698294

Fax +55 6232698294

Email pneumohc@uol.com.br
Background: Chronic obstructive pulmonary disease (COPD) is often underdiagnosed, which might be attributable to a lack of knowledge about the disease among the general population. The objective of this study was to evaluate COPD-related knowledge among primary care users in an urban area in Brazil.

Methods: This study was carried out at primary care clinics (PCCs), including 12 general PCCs and 26 family health PCCs, in the city of Goiânia, Brazil. Between May 2013 and February 2014, we interviewed 674 PCC users, applying a questionnaire designed to assess COPDrelated knowledge. Satisfactory knowledge of COPD was defined as knowing at least two of its symptoms and that smoking is a risk factor for the disease.

Results: Of the 674 users interviewed, only 9.2\% recognized the term "COPD", $75.1 \%$ recognized the term "emphysema", and $15.7 \%$ did not recognize either term. We found that recognizing either term was associated with a higher level of education $(P<0.001)$. The prevalence of satisfactory knowledge of COPD was $16.2 \%$, and having such knowledge was associated with being over 60 years of age. The COPD symptom known by the greatest proportion of users $(70.6 \%)$ was dyspnea, and most (87.5\%) knew that smoking is a risk factor, whereas only a few $(4.9 \%)$ knew that exposure to wood smoke is also a risk factor. The most frequently cited sources of knowledge were the media (43.1\%) and a relative with COPD (36.4\%).

Conclusion: Most of the PCC users evaluated did not know the term "COPD" but were familiar with the term "emphysema". The level of basic knowledge about the disease was low in this population. These results should alert health care administrators to the need for interventions aimed at increasing the diagnosis rate and thus promoting the early treatment of COPD.

Keywords: primary care, underdiagnosis, health professional, perception

\section{Introduction}

Chronic obstructive pulmonary disease (COPD) is a serious public health problem. According to the World Health Organization (WHO), ${ }^{1} \mathrm{COPD}$ is the sixth leading cause of death worldwide and is predicted to be the third leading cause by 2020 . However, COPD is still little known and has been underdiagnosed..$^{2,3}$ In a study conducted in a large city in the central-west region of Brazil, ${ }^{2}$ the rate of underdiagnosis of COPD among individuals presenting risk factors at primary care clinics (PCCs) was found to be $71.4 \%$, and the authors found that spirometry was used as a diagnostic tool in only $1.5 \%$ of those cases. PLATINO (Latin American Project for the Investigation of Obstructive Lung Disease) study, conducted in 2005 in the city of São Paulo, Brazil, ${ }^{3}$ demonstrated that $87.5 \%$ of COPD patients had been diagnosed in the later stages of the disease. The underdiagnosis of COPD is a problem worldwide. ${ }^{4}$ The authors of a 
study conducted in Canada concluded that it is a challenge to evaluate knowledge about COPD because many individuals do not know the term "COPD" or any details regarding the disease, reporting that $13 \%$ of the at-risk population in Canada has no such knowledge. ${ }^{5}$

In view of the possibility that a lack of knowledge about COPD among health care users is one of the causes of its underdiagnosis, the objective of this study was to analyze the level of such knowledge, as well as the factors associated with gaining that knowledge, among users of PCC services in an urban area in Brazil.

\section{Methods}

This was an analytic, observational, cross-sectional study carried out between May 2013 and February 2014 in the PCCs of the city of Goiânia, Brazil, which has a population of approximately 1.3 million. At 12 general PCCs and 26 family health PCCs, we systematically recruited users (persons awaiting medical attention for various problems, regardless of whether or not they had been diagnosed with COPD) for face-to-face interviews. The interviewer started with the users who were waiting to the left of the unit entrance door and continued clockwise to the positions 9, 12, and 3 o'clock, in order to avoid recruiting users close to a previous respondent. Only individuals $\geq 40$ years of age were selected for interview.

To evaluate user knowledge of COPD, we employed an adapted version of a questionnaire originally developed for use in a study conducted in Spain, ${ }^{6}$ which has been employed in other, similar studies. Interviewees were asked whether they were familiar with the term "COPD" or with the term "emphysema". Those who recognized either of those terms were then asked if they could list any of the symptoms of the disease or the risk factors associated with it. They were also asked to cite the source of their COPD-related knowledge. If an interviewee did not recognize either term, the interview was concluded.

All participating users were interviewed face-to-face. The interviews were conducted by the lead researcher (a doctoral student of pulmonology) and by pulmonology residents trained by the lead researcher. The interviews included questions related to the following aspects: recognition of the term "COPD" or the term "emphysema"; knowledge of the symptoms of the disease (cough, expectoration, and dyspnea) and of the major risk factors (smoking or exposure to smoke from a wood-burning stove); and the source of the COPD-related knowledge. All participants gave written informed consent.

\section{Statistical analysis}

Data were analyzed with the Statistical Package for Social Sciences (SPSS for Windows, Version 15.0; SPSS, Inc., Chicago, IL, USA). A satisfactory level of knowledge of the disease was defined as being able to identify at least two or the three main symptoms (cough, expectoration, and dyspnea) and the major risk factor (smoking). ${ }^{7}$ Bivariate analyses were performed with the chi-square test, including the following variables: recognition of the term "COPD" or of the term "emphysema"; and satisfactory level of knowledge about the disease. Sex, age, and information about COPD obtained from physicians and relatives that showed values of $P<0.10$ were included in a multivariate model. The adjusted association measure was the incidence rate ratio and its respective 95\% confidence intervals estimated by robust Poisson regression.

\section{Power calculation}

To evaluate knowledge about COPD among PCC users, we calculated the optimal sample size to be 692 subjects, taking into consideration an expected prevalence of COPDrelated knowledge of $10 \%,{ }^{6}$ an error of $3 \%$, and a design effect of 1.8 .

\section{Ethics}

This study was approved by the Research Ethics Committee of the Federal University of Goiás Hospital das Clínicas (protocol number CEP/HC/UFG 067/12).

\section{Results}

During the study period, we interviewed a total of 674 PCC users. Of those 674 users, $84.3 \%$ recognized the term "COPD" or the term "emphysema" $(9.2 \%$ reported knowing only the first term and $75.1 \%$ knowing only the second term). We found that recognizing either term was associated with having a higher level of education $(P<0.001)$, although not with age, sex, or smoking (Table 1).

The COPD symptom known by the greatest proportion of users $(70.6 \%)$ was dyspnea, compared with only $2.7 \%$ for cough and $2.3 \%$ for expectoration. Most of the interviewees $(87.5 \%)$ knew that smoking is a risk factor for the disease, whereas only a few (4.9\%) knew that exposure to wood smoke is also a risk factor (Table 2). The sources of COPD-related knowledge most frequently cited by the respondents were the media $(43.1 \%)$ or a relative with COPD (36.4\%), followed by friends (28.5\%), physicians $(23.1 \%)$, and pharmacists $(2.6 \%)$.

The prevalence of satisfactory knowledge about the disease among the PCC users interviewed was $16.2 \%$. 
Table I Variables associated with recognition of the term "COPD" or the term "emphysema" among primary care clinic users in Goiânia, Brazil, 20I3-20I4

\begin{tabular}{|c|c|c|c|c|}
\hline \multirow[t]{3}{*}{ Variable } & \multicolumn{2}{|c|}{$\begin{array}{l}\text { Recognition of “COPD” } \\
\text { or "emphysema" }\end{array}$} & \multirow[t]{3}{*}{$\frac{\text { Total }}{n}$} & \multirow[t]{3}{*}{$P^{a}$} \\
\hline & Yes & No & & \\
\hline & n (\%) & n (\%) & & \\
\hline \multicolumn{5}{|l|}{ Age } \\
\hline$<60$ years & $367(85.5)$ & $62(14.5)$ & 429 & 0.229 \\
\hline$\geq 60$ years & $201(82.0)$ & $44(18.0)$ & 245 & \\
\hline \multicolumn{5}{|l|}{ Sex } \\
\hline Female & $362(86.2)$ & $58(13.8)$ & 420 & 0.079 \\
\hline Male & $206(8 I . I)$ & $48(18.9)$ & 254 & \\
\hline \multicolumn{5}{|l|}{ Years of schooling } \\
\hline$\leq 4$ & $233(77.9)$ & $66(22.1)$ & 299 & $<0.001$ \\
\hline $5-8$ & $156(84.8)$ & $28(15.2)$ & 184 & \\
\hline$\geq 9$ & $179(93.7)$ & $12(6.3)$ & 191 & \\
\hline \multicolumn{5}{|l|}{ Smoking status } \\
\hline Smoker & $71(83.5)$ & $14(16.5)$ & 85 & 0.878 \\
\hline Former smoker & I $87(83.5)$ & $37(16.5)$ & 224 & \\
\hline Nonsmoker & $310(84.9)$ & $55(15.1)$ & 365 & \\
\hline Total & $568(84.3)$ & $106(15.7)$ & 674 & \\
\hline
\end{tabular}

Note: a Obtained by chi-square test.

Abbreviation: COPD, chronic obstructive pulmonary disease.

Of the individuals who recognized either term for the disease (“COPD" or "emphysema"), 19.2\% also presented satisfactory knowledge about it. As can be seen in Table 3, the bivariate analysis showed that satisfactory knowledge of COPD correlated significantly with the $\geq 60$ years age bracket and the "relative with COPD" source of knowledge $(P=0.011$ and $P=0.002$, respectively).

After adjustment, the variables that remained independently associated with satisfactory knowledge of COPD among the PCC users evaluated were the $\geq 60$ years age bracket and the "relative with COPD" source of knowledge (Table 4). There were no statistically significant differences in relation to the variables sex, level of education, or smoking status.

Table 2 Knowledge of COPD symptoms and risk factors among users who recognized the term "COPD" or the term "emphysema" at primary care clinics in Goiânia, Brazil, 20I3-2014

\begin{tabular}{ll}
\hline Variables & $\begin{array}{l}\text { Users recognizing “COPD” } \\
\text { or “emphysema" (n=568) }\end{array}$ \\
\hline $\begin{array}{ll}\text { Knowledge of COPD symptoms, n (\%) } \\
\text { Dyspnea }\end{array}$ & $40 \mathrm{I}(70.6)$ \\
Cough & $15(2.7)$ \\
$\quad$ Expectoration & $13(2.3)$ \\
Knowledge of COPD risk factors, n (\%) & \\
$\quad$ Tobacco & $497(87.5)$ \\
Wood smoke & $28(4.9)$ \\
\hline
\end{tabular}

Abbreviation: COPD, chronic obstructive pulmonary disease.
Table 3 Factors associated with satisfactory knowledge of COPD among primary care clinic users in Goiânia, Brazil, 20I3-20I4

\begin{tabular}{|c|c|c|c|c|}
\hline & \multicolumn{2}{|c|}{$\begin{array}{l}\text { Satisfactory knowledge } \\
\text { of COPD }\end{array}$} & \multirow[t]{3}{*}{$\begin{array}{l}\text { Total } \\
(\mathrm{N}=674)\end{array}$} & \multirow[t]{3}{*}{$P^{a}$} \\
\hline & Yes & No & & \\
\hline & n (\%) & n (\%) & & \\
\hline \multicolumn{5}{|l|}{ Age } \\
\hline$<60$ years & $59(16.1)$ & $308(83.9)$ & 367 & \multirow[t]{2}{*}{0.011} \\
\hline$\geq 60$ years & $50(24.9)$ & $151(75.1)$ & 201 & \\
\hline \multicolumn{5}{|l|}{ Sex } \\
\hline Female & $75(20.7)$ & $287(79.3)$ & 362 & \multirow[t]{2}{*}{0.220} \\
\hline Male & $34(16.5)$ & $172(83.5)$ & 206 & \\
\hline \multicolumn{5}{|l|}{ Years of schooling } \\
\hline$\leq 4$ & $47(20.2)$ & I $86(79.8)$ & 233 & \multirow[t]{3}{*}{0.124} \\
\hline $5-8$ & $36(23.1)$ & $120(76.9)$ & 156 & \\
\hline$\geq 9$ & $26(14.5)$ & $153(85.5)$ & 179 & \\
\hline \multicolumn{5}{|l|}{ Smoking status } \\
\hline Smoker & $13(18.3)$ & $58(81.7)$ & 71 & \multirow[t]{3}{*}{0.959} \\
\hline Former smoker & $37(19.8)$ & $150(80.2)$ & 187 & \\
\hline Nonsmoker & $59(19.0)$ & $25 I(8 I .0)$ & 310 & \\
\hline \multicolumn{5}{|c|}{ Information source } \\
\hline \multicolumn{5}{|c|}{ Media } \\
\hline Yes & $47(17.3)$ & $224(82.7)$ & 271 & \multirow[t]{2}{*}{0.286} \\
\hline No & $62(20.9)$ & $235(79.1)$ & 297 & \\
\hline \multicolumn{5}{|l|}{ Physician } \\
\hline Yes & $32(24.4)$ & $99(75.6)$ & $13 \mid$ & \multirow[t]{2}{*}{0.083} \\
\hline No & 77 (I7.6) & $360(82.4)$ & 437 & \\
\hline \multicolumn{5}{|l|}{ Pharmacist } \\
\hline Yes & $5(33.3)$ & $10(66.7)$ & 15 & \multirow[t]{2}{*}{0.180} \\
\hline No & $104(18.8)$ & 449 (8I.2) & 553 & \\
\hline \multicolumn{5}{|l|}{ Relative } \\
\hline Yes & $54(26.1)$ & I53 (73.9) & 207 & \multirow[t]{2}{*}{0.002} \\
\hline No & $55(15.2)$ & $306(84.8)$ & 361 & \\
\hline \multicolumn{5}{|l|}{ Friends } \\
\hline Yes & $36(22.2)$ & I 26 (77.8) & 162 & \multirow[t]{2}{*}{0.246} \\
\hline No & $73(18.0)$ & $333(82.0)$ & 406 & \\
\hline
\end{tabular}

Note: a Obtained by chi-square test.

Abbreviation: COPD, chronic obstructive pulmonary disease.

\section{Discussion}

The data collected show that $9.2 \%$ of the population studied recognized the term "COPD", regardless of whether they had presented symptoms or had been diagnosed with the disease, and we identified a positive association between possessing such knowledge and the level of education. This finding corroborates those of the BREATHE study, ${ }^{8}$ conducted in the Middle East and North Africa, which also showed that possessing COPD-related knowledge was associated with the level of education.

\section{Comparisons with other studies}

Various authors have reported a lack of knowledge on the part of the general population in relation to the term "COPD" and its meaning as a respiratory disease. 6 ,9 Two studies 
Table 4 Predictors of satisfactory knowledge of COPD among primary care clinic users ( $\mathrm{N}=674)$ in Goiânia, Brazil, 20I3-20I4

\begin{tabular}{llll}
\hline Variable & IRR $^{\mathbf{a}}$ & $\mathbf{9 5 \%} \mathbf{C l}$ & $\boldsymbol{P}$ \\
\hline Female sex & 1.21 & $0.83-1.78$ & 0.306 \\
Age $\geq 60$ years & 1.52 & $1.08-2.15$ & 0.017 \\
$\begin{array}{l}\text { Information about COPD } \\
\text { obtained from physicians }\end{array}$ & 1.31 & $0.91-1.87$ & 0.142 \\
$\begin{array}{l}\text { Information about COPD } \\
\text { obtained from relatives }\end{array}$ & 1.63 & $1.16-2.30$ & 0.005 \\
\hline
\end{tabular}

Note: aObtained by robust Poisson multiple regression.

Abbreviations: $\mathrm{Cl}$, confidence interval; COPD, chronic obstructive pulmonary disease; IRR, incidence rate ratio.

conducted in Spain ${ }^{6,9}$ respectively found that only $17.0 \%$ and $8.6 \%$ of symptomatic individuals in the general population recognize the term "COPD". In a study evaluating knowledge and the perception of COPD in the general population of France,${ }^{10}$ it was reported that only $8 \%$ of at-risk individuals could define the term "COPD", whereas $69 \%$ knew the term "emphysema", and only 66\% associated the term "COPD" with respiratory diseases. Emphysema is a term used in histology and is often incorrectly used in clinical practice. This term has been assimilated by the population in general and describes only one aspect of COPD. It should be borne in mind that the presence of chronic cough and expectoration can precede or follow the development of airflow limitation. Patients can present with symptoms of chronic bronchitis even when their spirometry results are normal. ${ }^{7}$

Our findings suggest that health education must be emphasized for individuals with a low level of education. The term "emphysema" can be initially employed as a synonym of COPD and gradually replaced in health education programs. In addition, our data reveal that the lack of knowledge about the disease does not differ in relation to sex, age, or smoking status, and smokers (the at-risk population) present the same (low) level of COPD-related knowledge as do nonsmokers.

We have shown that the prevalence of COPD-related knowledge is low among PCC users in general as well as that the proportion of individuals with more specific knowledge of the disease is low even among those who recognize either of the terms proffered ("COPD" or "emphysema"). Some authors have attempted to determine the prevalence of COPD-related knowledge in the general population and in symptomatic smokers. ${ }^{5,6,8,9,11}$ In Africa, ${ }^{8}$ a lack of such knowledge was identified even among individuals with respiratory symptoms. In the previously cited study conducted in Canada, ${ }^{5} 60 \%$ of the individuals at risk of developing COPD knew little or nothing about the disease. In regions of Spain, ${ }^{6}$ that rate ranges from $73.7 \%$ to $91.0 \%$. In another study conducted in Canada, ${ }^{11}$ COPD patients showed a great lack of knowledge about the causes, symptoms, and treatment of their disease.

Among the variables considered here, only being over 60 years of age was associated with possessing satisfactory knowledge of COPD, which is in agreement with the findings of one of the studies conducted in Canada. ${ }^{5}$ In one of the studies conducted in Spain, ${ }^{9}$ the authors found that only 8.6\% of the surveyed population had any spontaneous knowledge about COPD. In both of the studies conducted in Spain, ${ }^{6,9}$ that proportion was found to correlate negatively with advancing age. The discrepancy between those studies and the present study is probably explained by the differences between the populations studied.

As previously mentioned, the COPD symptom most often known by the PCC users evaluated in the present study was dyspnea, and only a minority knew that cough and expectoration are also symptoms of the disease. These data corroborate those reported in one of the studies conducted in Spain, ${ }^{6}$ in which the most commonly cited symptoms of COPD were dyspnea (81.1\%), cough (29.0\%), and expectoration $(10.6 \%)$. Dyspnea presupposes a more advanced stage of the disease and is common to various diseases, while cough and expectoration are initial symptoms of COPD and allow an earlier diagnosis. Therefore, it is of utmost importance to emphasize the early symptoms of the disease in health education programs. The lack of knowledge about the early symptoms of COPD could explain the fact that patients do not seek treatment in a timely fashion. In Brazil, the PLATINO study showed that the patients with previous knowledge on the disease were those who were the most symptomatic. ${ }^{3}$

In the present study, most of the respondents with satisfactory knowledge of COPD mentioned smoking as a risk factor. However, among the $13 \%$ who did not mention this risk factor were some smokers of an at-risk age. Several authors have attempted to evaluate systematically the level of risk factor recognition in the general population. ${ }^{6,8-10,12}$ Those authors reported that the majority of the interviewed individuals identified smoking as risk factor. In the BREATHE study, ${ }^{8} 81 \%$ of the interviewees recognized smoking as a COPD risk factor.

We found that exposure to smoke from a wood-burning stove was recognized as a COPD risk factor by less than 5\% of the respondents. In a region where the habit of cooking with wood-burning stoves is still relevant, exposure to wood smoke is a major risk factor. ${ }^{13}$ In Poland, ${ }^{14} 52 \%$ of the women diagnosed with COPD were never-smokers who reported cooking with coal and wood. The information that biomass burning is a risk factor must be effectively transmitted, to health professionals and the population in general, through 
continuing education programs aiming to decrease the rate of COPD underdiagnosis in nonsmokers.

When planning health education programs, administrators should take into consideration the various sources of knowledge concerning COPD. In a study conducted in the Middle East and North Africa (the BREATHE study), ${ }^{8}$ as well as in a study conducted in the United States, ${ }^{15}$ most of the interviewees with suspected COPD (66.6\% and 77\%, respectively) reported having received information about COPD from their physicians. Those results differ from ours, probably because the individuals targeted in those two studies presented with clinical suspicion of or had been diagnosed with COPD, having already consulted physicians. However, our results are corroborated by those of the two studies conducted in Spain, 6,9 whose authors also reported that the media was cited by the general population as one of the main sources of knowledge about COPD (47.0\% and 39.8\%, respectively).

\section{Implications}

Given that the media has been cited as the major source of information and that the general population has such little knowledge of COPD, we can suggest that the media is not being used to its full potential as a source of medical information. In addition, given the low level of knowledge regarding COPD on the part of the general population, we would have expected that the individuals within the at-risk portion of our sample (those over 40 years of age, $54.3 \%$ of whom were smokers or former smokers) would have more often reported getting information from physicians. In other words, we found that physicians did not make a significant contribution to disseminating knowledge about COPD, and we believe that their contribution could have been greater.

It is fundamental to invest in educating medical staff through training programs, especially in primary care, to improve the treatment of patients with COPD. Education programs designed to raise awareness of COPD among the general population are also needed, in order to promote early recognition of the signs of the disease and encourage individuals to seek treatment in a timely manner. ${ }^{1}$ One important step in that direction would be the creation of a national COPD treatment program, to be implemented at PCCs, one of the objectives of which would be active surveillance for new cases of COPD. ${ }^{1}$

\section{Strengths and limitations}

The present study has a number of strengths. First, it was carried out in a large city with a structured primary health care system. In addition, the interviews were conducted in person and by pulmonologists (rather than through online surveys, which have been used in several studies). One limitation of our study is that we did not evaluate a group of patients with suspected or confirmed COPD within the study sample. However, the main focus of the study was the general population, which is an important target for health education.

\section{Conclusion}

The underdiagnosis of COPD could be attributable to the lack of knowledge on the part of the general population, the limited use of diagnostic procedures on the part of physicians, or both. Research conducted in primary care settings has not answered all the questions about the probable causes of such underdiagnosis. Further studies are therefore needed in order to identify the causes of COPD underdiagnosis, especially in developing countries. Such studies could help health care administrators carry out interventions aimed at increasing the diagnosis rate and promoting the early treatment of COPD.

\section{Acknowledgment}

This study received financial support from the Fundação de Amparo à Pesquisa do Estado de Goiás (FAPEG) (Foundation for the Support of Research in the State of Goiás).

\section{Disclosure}

The authors report no conflicts of interest in this work.

\section{References}

1. who.int [homepage on the Internet]. World Health Organization; 2007 [cited March 18, 2013]. Available from: http://www.who.int/respiratory/ copd/burden/en/. Accessed September 26, 2014.

2. Queiroz MCCA, Moreira MAC, Rabahi MF. Underdiagnosis of COPD at primary health care clinics in the city of Aparecida de Goiânia, Brazil. J Bras Pneumol. 2012;38(6):692-699. Spanish.

3. Menezes AM, Perez-Padilla R, Jardim JR, et al; PLATINO Team. Chronic obstructive pulmonary disease in five Latin American cities (the PLATINO study): a prevalence study. Lancet. 2005;366(9500):1875-1881.

4. Buist AS, McBurnie MA, Vollmer WM, et al; BOLD Collaborative Research Group. International variation in the prevalence of COPD (the BOLD Study): a population-based prevalence study. Lancet. 2007; 370(9589):741-750.

5. Walker SL, Saltman DL, Colucci R, Martin L; Canadian Lung Association Advisory Committee. Awareness of risk factors among persons at risk for lung cancer, chronic obstructive pulmonary disease and sleep apnea: a Canadian population-based study. Can Respir J. 2010;17(6): 287-294.

6. Soriano JB, Calle M, Montemayor T, Alvarez-Sala JL, Ruiz-Manzano J, Miravitlles M. The general public's knowledge of chronic obstructive pulmonary disease and its determinants: current situation and recent changes. Arch Bronconeumol. 2012;48(9):308-315.

7. Global Initiative for Chronic Obstructive Lung Disease. Global Strategy for the Diagnosis, Management, and Prevention of Chronic Obstructive Lung Disease (Revised 2011). Vancouver, WA: Global Initiative for Chronic Obstructive Lung Disease; 2011. Available from: http://www. goldcopd.org/uploads/users/files/GOLD_Report_2011_Feb21.pdf. Accessed December 26, 2011. 
8. Sayiner A, Alzaabi A, Obeidat NM, et al; BREATHE Study Group. Attitudes and beliefs about COPD: data from the BREATHE study. Respir Med. 2012;106 Suppl 2:S60-S74.

9. Miravitlles M, de la Roza C, Morera J, et al. Chronic respiratory symptoms, spirometry and knowledge of COPD among general population. Respir Med. 2006;100(11):1973-1980.

10. Roche N, Perez T, Neukirch F, et al. High prevalence of COPD symptoms in the general population contrasting with low awareness of the disease. Rev Mal Respir. 2011;28(7):e58-e65.

11. Hernandez P, Balter M, Bourbeau J, Hodder R. Living with chronic obstructive pulmonary disease: a survey of patients' knowledge and attitudes. Respir Med. 2009;103(7):1004-1012.

12. Llauger Roselló MA, Pou MA, Domínguez L, Freixas M, Valverde P, Valero C; Grup Emergent de Recerca en Malalties Respiratòries (Unitat de Suport a la Recerca de Barcelona-IDIAP Jordi Gol) [Treating COPD in chronic patients in a primary-care setting]. Arch Bronconeumol. 2011;47(11):561-570. Spanish.
13. Moreira MA, Barbosa MA, Jardim JR, Queiroz MC, Inácio LU. Chronic obstructive pulmonary disease in women exposed to wood stove smoke. Rev Assoc Med Bras. 2013;59(6):607-613.

14. Bednarek M, Maciejewski J, Wozniak M, Kuca P, Zielinski J. Prevalence, severity and underdiagnosis of COPD in the primary care setting. Thorax. 2008;63(5):402-407.

15. Barr RG, Celli BR, Martinez FJ, et al. Physician and patient perceptions in COPD: the COPD Resource Network Needs Assessment Survey. Am J Med. 2005;118(12):1415.

\section{Publish your work in this journal}

The International Journal of COPD is an international, peer-reviewed journal of therapeutics and pharmacology focusing on concise rapid reporting of clinical studies and reviews in COPD. Special focus is given to the pathophysiological processes underlying the disease, intervention programs, patient focused education, and self management protocols.

\section{Dovepress}

This journal is indexed on PubMed Central, MedLine and CAS. The manuscript management system is completely online and includes a very quick and fair peer-review system, which is all easy to use. Visit http://www.dovepress.com/testimonials.php to read real quotes from published authors.

Submit your manuscript here: http://www.dovepress.com/international-journal-of-copd-journal 